\title{
Magnetic Relaxation-Based Sensing of Phosphate Ion
}

\author{
Tevhide Ozkaya Ahmadov, Peng Wang, Haohan Zhao, Peng Zhang* \\ Department of Chemistry, University of Cincinnati, Cincinnati, OH 45221
}

Corresponding author: Peng Zhang, Tel: 513-556-9222. Email: peng.zhang@uc.edu

\begin{abstract}
We report a novel magnetic relaxation-based sensing method for sensitive and selective detection of phosphate ions in aqueous media using paramagnetic nanoparticles. The method can detect phosphate ions at physiological $\mathrm{pH}$ quantitatively with high selectivity, even in a commercial fertilizer without separation.
\end{abstract}

\section{KEYWORDS}

Phosphate ion; magnetic relaxation; paramagnetic nanoparticles 


\section{Introduction}

Phosphate anion is one of the most abundance species on the earth surface, and plays vital roles in living systems [1]. It is crucial for many biological processes. Yet high amounts of phosphate can disrupt the balance of the ecosystem [2,3]. Uses of phosphate-containing fertilizers and detergents are the main sources of the increase of phosphate concentration in the environment [4-6]. Pollution from phosphate and phosphorylated compounds is one of the main reasons for the eutrophication of natural water sources, which is leading to a dangerous increase in the toxic algal blooms [7]. According to US EPA, accelerated eutrophication is one of the major problems facing the Nation's lakes and reservoirs [8]. Depletion of dissolved oxygen as a result of eutrophication due to the overabundance of phosphate in water can subsequently cause a variety of problems, including low water quality and death of aquatic life [9-11].

Therefore, there is an ongoing need for sensors that can determine phosphate concentrations accurately and preferably in real-time. The need of phosphate ion sensors in the field of environmental, industrial, and medicinal analysis is driving researchers to develop new methods for the fast, accurate, reproducible, and selective detection of phosphate over a wide range of concentrations in various samples with sufficient sensitivity [12-15]. Thus far, there have been many kinds of methods for the determination of phosphate, including electrochemistry [16], UV-vis spectroscopy [17], chromatography [18], fluorescence spectroscopy [19], and enzymatic biosensors [20]. However, most of these methods use organic solvents as the detection media. The detection of phosphate in aqueous solutions, hence, remains a challenge [21].

Nuclear magnetic relaxation (MR) based sensing has been one of the emerging methods that promise fast and reliable results for detection of targets in aqueous solutions using nuclear magnetic resonance (NMR) relaxometer [22-25]. These methods are based on the use of surface-functionalized magnetic nanoparticles (MNPs), typically superparamagnetic iron oxide nanoparticles, to detect specific 
targets in a variety of mixture without any separation or washing steps [26]. Interaction of targets with MNPs leads to a significant change in the transverse relaxation time $\left(\mathrm{T}_{2}\right)$ of water protons in the solution [27-30].

Paramagnetic metal ions, such as $\mathrm{Gd}^{3+}, \mathrm{Fe}^{3+}, \mathrm{Mn}^{2+}, \mathrm{Mn}^{3+}$ and $\mathrm{Cu}^{2+}$, in aqueous solutions can affect the longitudinal $\left(\mathrm{T}_{1}\right)$ and transverse $\left(\mathrm{T}_{2}\right)$ relaxation times of the surrounding water protons. Their chelates can serve as contrast agents in magnetic resonance imaging (MRI) [31-33]. In our previous study, we showed that nanoparticles with chelated paramagnetic metal ions could also be used for MRbased sensing [34]. Compared to the more commonly used superparamagnetic iron oxide nanoparticles, such nanoparticles are less likely to become aggregated, which would affect the detection.

Herein we report a nuclear magnetic relaxation based method that can detect phosphate ions in aqueous solution without separation. Unlike our previous study, where $\mathrm{Fe}^{3+}$ ions served as the paramagnetic agents, $\mathrm{Gd}^{3+}$ ions are used in this work, taking advantage of their high magnetic moment and good stability at physiological $\mathrm{pH}[35,36]$.

\section{Materials and methods}

\subsection{Chemicals and materials}

(Trimethoxysilylpropyl)ethyldiaminetriacetic acid trisodium salt (TMS-EDTA) (35 wt\% solution in water) was purchased from Gelest. Tetraethylorthosilicate (TEOS), Triton X-100 (TX-100), n-hexanol, cyclohexane, ammonium hydroxide (30 wt\%), gadolinium (III) chloride hexahydrate, $\mathrm{KH}_{2} \mathrm{PO}_{4}$ and glacial acetic acid were from Sigma-Aldrich. Fertilizer (Schultz Expert Gardener) was purchased from a local store. All chemicals were used without further purification. Deionized (DI) water (18 M $\Omega-\mathrm{cm})$ was used for the preparation of all solutions.

\subsection{Synthesis of $\mathbf{G d}^{3+}$-chelated $\mathrm{SiO}_{2}$ nanoparticles $\left(\mathrm{SiO}_{2} @ \mathbf{T M S}-\mathrm{EDTA} @ \mathrm{Gd}^{3+}\right)$}


Paramagnetic $\mathrm{SiO}_{2} @ \mathrm{TMS}-\mathrm{EDTA} @ \mathrm{Gd}^{3+}$ nanoparticles were prepared in two steps following a modified version of the previously published protocol [34]. First, $\mathrm{SiO}_{2} @$ TMS-EDTA nanoparticles with EDTA groups on surface were synthesized by mixing $1.77 \mathrm{~g}$ Triton $\mathrm{X}-100,7.5 \mathrm{~mL}$ cyclohexane, $1.6 \mathrm{~mL}$ n-hexanol, and $480 \mu \mathrm{L}$ DI water in a glass vial and stirring for $5 \mathrm{~min}$ to form a microemulsion system. Next, $60 \mu \mathrm{L}$ of $\mathrm{NH}_{4} \mathrm{OH}$ was added to the microemulsion and stirred for $20 \mathrm{~min}$, followed by the addition of $50 \mu \mathrm{L}$ TEOS. The mixture was stirred at room temperature for $24 \mathrm{~h}$. Then, $50 \mu \mathrm{L}$ of TEOS was added to the microemulsion and stirred for $30 \mathrm{~min}$, and finally $25 \mu \mathrm{L}$ of TMS-EDTA was added, followed by another $24 \mathrm{~h}$ stirring. Subsequently, approximately $20 \mathrm{~mL}$ of acetone was added to disrupt the microemulsion system. $\mathrm{SiO}_{2} @$ TMS-EDTA nanoparticles were recovered by centrifuging the mixture at $14000 \mathrm{rpm}$ for $20 \mathrm{~min}$, and then washed three times with acetone, ethanol and DI water, respectively. The resulting $\mathrm{SiO}_{2} @$ TMS-EDTA nanoparticles were dispersed in DI water. The $\mathrm{SiO}_{2} @ \mathrm{TMS}-\mathrm{TDTA}$ nanoparticles were mixed with excess amount of $0.1 \mathrm{M} \mathrm{GdCl}_{3}$ solution and stirred overnight at $40{ }^{0} \mathrm{C}$. The resulting $\mathrm{SiO}_{2} @ \mathrm{TMS}-\mathrm{EDTA} @ \mathrm{Gd}^{3+}$ nanoparticles were washed three times with DI water and then dispersed in $20 \mathrm{mM}$ of tris buffer $(\mathrm{pH} 7.5)$ for storage.

\subsection{Characterizations of nanoparticles}

TEM measurements were done on a Biotwin 12 transmission electron microscope. The amount of $\mathrm{Gd}^{3+}$ ions in $\mathrm{SiO}_{2} @ \mathrm{TMS}-\mathrm{EDTA} @ \mathrm{Gd}^{3+}$ nanoparticle solution was determined by ICP-MS. The quantification was carried out by external five-point-calibration between 10 and 10,000 ug/L $\mathrm{GdCl}_{3}$ in $\mathrm{HNO}_{3}(3 \% \mathrm{v} / \mathrm{v}) . \mathrm{GdCl}_{3}$ stock solutions were diluted with $3 \% \mathrm{HNO}_{3}$ solution to relevant concentration levels. Separately, $0.1 \mathrm{~mL}$ of $\mathrm{SiO}_{2} @ \mathrm{TMS}-\mathrm{EDTA} @ \mathrm{Gd}^{3+}$ nanoparticle sample was mixed with $0.9 \mathrm{~mL}$ of $1 \mathrm{M} \mathrm{HCl}: \mathrm{NaF}(1: 1)$ solution, and heated at $80{ }^{\circ} \mathrm{C}$ overnight to fully digest the silica nanostructures and release $\mathrm{Gd}^{3+}$ ions. The resulting sample was further diluted using $3 \% \mathrm{HNO}_{3}$ solution for measurements, which were carried out on an Agilent 7700 CE inductively coupled plasma mass spectrometer. 


\subsection{Nuclear magnetic relaxation measurements}

Transverse relaxation times $\left(T_{2}\right)$ were measured at $1.41 \mathrm{~T}$ on a Bruker Minispec mq60 relaxometer operating at $40{ }^{\circ} \mathrm{C}$. For the nuclear magnetic relaxation measurements, Carr-PurcellMeiboom-Gill (CPMG) spin-echo pulse sequences were used to limit the effect of magnetic inhomogeneity of instrument [31].

\subsection{Detection of phosphate ions}

$\mathrm{KH}_{2} \mathrm{PO}_{4}$ stock solution was first prepared, and serially diluted. In a typical run, $\mathrm{T}_{2}$ measurements of the $\mathrm{SiO}_{2} @ \mathrm{TMS}-\mathrm{EDTA} @ \mathrm{Gd}^{3+}$ nanoparticles in tris buffer $(\mathrm{pH} 7.5)$ were first taken at $40{ }^{\circ} \mathrm{C}$. Then, $\mathrm{KH}_{2} \mathrm{PO}_{4}$ samples were added to the $\mathrm{SiO}_{2} @ \mathrm{TMS}-\mathrm{EDTA} @ \mathrm{Gd}^{3+}$ nanoparticle solution and incubated for 6 $\mathrm{h}$ at $40{ }^{\circ} \mathrm{C}$ before the $\mathrm{T}_{2}$ measurements were taken again. To test the specificity of the sensing method, several $\mathrm{SiO}_{2} @$ TMS-EDTA@ $\mathrm{Gd}^{3+}$ nanoparticle solutions were prepared in tris buffer. Then $1 \mathrm{~mL}$ solutions containing $0.1 \mathrm{M}$ of $\mathrm{CO}_{3}{ }^{2-}$, acetate, $\mathrm{Cl}^{-}, \mathrm{F}^{-}, \mathrm{NO}_{3}{ }^{-}, \mathrm{H}_{2} \mathrm{PO}_{4}^{-}$and $\mathrm{SO}_{4}{ }^{2-}$, respectively, were prepared and added to each of the $\mathrm{SiO}_{2} @ \mathrm{TMS}-\mathrm{EDTA} @ \mathrm{Gd}^{3+}$ nanoparticle solutions to reach an anion concentration of $4 \mathrm{mM}$ in each sample. $\mathrm{T}_{2}$ measurements were taken after $6 \mathrm{hr}$ of incubation.

In the case of determining phosphate ions in fertilizer, one gram of fertilizer was dissolved in DI water and then serially diluted. Fertilizer samples were introduced to the $\mathrm{SiO}_{2} @ \mathrm{TMS}-\mathrm{EDTA} @ \mathrm{Gd}^{3+} \mathrm{NPs}$ in tris buffer. After incubation for $6 \mathrm{hr}, \mathrm{T}_{2}$ measurements were taken.

\section{Results and discussion}

The principle of the sensing scheme is shown in Figure $1 . \mathrm{Gd}^{3+}$ chelates are the most commonly used contrast agents in magnetic resonance imaging (MRI) thanks to their high magnetic moment. In our design, $\mathrm{Gd}^{3+}$ ions are chelated and stabilized by the EDTA groups grafted on the surface of silica nanoparticles $\left(\mathrm{SiO}_{2} \mathrm{NPs}\right)$. The chelated $\mathrm{Gd}^{3+}$ ions are stable around physiological $\mathrm{pH}$ without forming 
the insoluble $\mathrm{Gd}^{3+}$ oxides. These $\mathrm{Gd}^{3+}$ ions would affect the relaxation rate of the surrounding water protons due to their access to water protons. Phosphate ions have strong affinity to $\mathrm{Gd}^{3+}$ ions [37-39] due to the thermodynamic stability of hard acid-hard base interaction. The presence of phosphate ions would bind to the $\mathrm{Gd}^{3+}$ ions, disturbing their access to water protons and subsequently resulting to the change in the $\mathrm{T}_{2}$ relaxation time of water protons in the solution. By monitoring the change of $\mathrm{T}_{2}$ of water protons we can quantitatively detect phosphate ions.

\section{[Figure 1]}

The synthesized $\mathrm{SiO}_{2} @ \mathrm{TMS}-\mathrm{EDTA} @ \mathrm{Gd}^{3+}$ nanoparticles were characterized by a number of techniques. The average diameters of the $\mathrm{SiO}_{2} @$ TMS-EDTA nanoparticles are $~ 60 \mathrm{~nm}$ according to transmission electron microscopy (TEM) as shown in Figure 2. The amount of $\mathrm{Gd}^{3+}$ ions in the $\mathrm{SiO}_{2} @ \mathrm{TMS}-\mathrm{EDTA} @ \mathrm{Gd}^{3+}$ nanoparticle stock solution was quantified using ICP-MS and determined to be $0.52 \mathrm{mg} / \mathrm{mL}$.

\section{[Figure 2]}

The transverse relaxivity $\left(\mathrm{R}_{2}\right)$ of the $\mathrm{SiO}_{2} @ \mathrm{TMS}-\mathrm{EDTA} @ \mathrm{Gd}^{3+}$ nanoparticles is determined by measuring the transverse relaxation times $\left(\mathrm{T}_{2}\right)$ of water protons of solutions containing different concentrations of $\mathrm{SiO}_{2} @ \mathrm{TMS}-\mathrm{EDTA} @ \mathrm{Gd}^{3+}$ nanoparticles. As shown in Figure 3, $\mathrm{R}_{2}$ of the $\mathrm{SiO}_{2} @ \mathrm{TMS}-\mathrm{TDTA} @ \mathrm{Gd}^{3+}$ nanoparticles is calculated to be $203.2 \mathrm{mM}^{-1} \mathrm{~s}^{-1}$, which is much higher than the clinically used Gd-DTPA complex $\left(4.6 \mathrm{mM}^{-1} \mathrm{~s}^{-1}\right)$ [40]. This is likely attributed to that the chelation with the pentadentate TMS-EDTA [41] leaves $\mathrm{Gd}^{3+}$ ion, which tends to form complexes with a 
coordination number of nine [42], with more available coordination sites to interact with water protons [43], as compared to the chelation of $\mathrm{Gd}^{3+}$ ion with DTPA.

\section{[Figure 3]}

The percentage change of $\mathrm{T}_{2}$ relaxation time $\left(\Delta \mathrm{T}_{2} \%\right)$ upon the binding of phosphate ions to $\mathrm{SiO}_{2} @ \mathrm{TMS}-E D T A @ \mathrm{Gd}^{3+}$ nanoparticles is calculated using the following equation $[42,44]$ :

$\Delta \mathrm{T}_{2} \%=\left(\mathrm{T}_{2, \text { target }}-\mathrm{T}_{2, \text { blank }}\right) \times 100 / \mathrm{T}_{2}$ blank

where $T_{2, \text { blank }}$ and $T_{2 \text {,target }}$ is the average $T_{2}$ relaxation time of three replicates of nanoparticle solution before and after the addition of phosphate ions, respectively.

We first test the working principle of this sensing method using pure $\mathrm{KH}_{2} \mathrm{PO}_{4}$ as the phosphate source. As shown in Figure 4, a significant increase in $\Delta \mathrm{T}_{2} \%$ occurs as a result of phosphate addition to the nanoparticle solution in tris buffer. A linear relationship between $\Delta \mathrm{T}_{2} \%$ and phosphate concentration is observed in the $\mu \mathrm{M}$ range with a correlation coefficient $\left(\mathrm{R}^{2}\right)$ of 0.9999 and a detection limit of 0.1 $\mu \mathrm{M}$.

\section{[Figure 4]}

To examine the specificity of this sensing method, the change in $\mathrm{T}_{2}$ relaxation time of water protons, as a result of interaction of $\mathrm{SiO}_{2} @ \mathrm{TMS}-\mathrm{EDTA} @ \mathrm{Gd}^{3+}$ nanoparticles with various common anions, including $\mathrm{CO}_{3}{ }^{2-}$, acetate, $\mathrm{Cl}^{-}, \mathrm{F}^{-}, \mathrm{NO}_{3}{ }^{-}, \mathrm{H}_{2} \mathrm{PO}_{4}^{-}$and $\mathrm{SO}_{4}{ }^{2-}$, was measured under the same conditions. The final concentration of all anions was set at $4 \mathrm{mM}$. Results are shown in Figure 5. Notice 
that only phosphate ions cause a significant increase in $\Delta \mathrm{T}_{2} \%$, while $\mathrm{F}^{-}$ions can slightly affect the $\Delta \mathrm{T}_{2} \%$. All other anions have negligible effect.

\section{[Figure 5]}

To test the utility of this sensing method in a complex matrix for actual applications, commercial phosphate-containing fertilizer was used in this study. The fertilizer contains the following ingredients as labeled: total nitrogen $20 \%$, available phosphate $30 \%$, soluble Potash $20 \%$, chelated iron $0.1 \%$, chelated Mn 0.05\%, and chelated Zn 0.05\%. Results shown in Figure 6 demonstrate that $\mathrm{SiO}_{2} @ \mathrm{TMS}-$ EDTA@ $\mathrm{Gd}^{3+}$ nanoparticles can detect phosphate content in the fertilizer quantitatively. A linear relationship between the concentration of phosphate in the fertilizer and $\Delta \mathrm{T}_{2} \%$ is observed in the $\mu \mathrm{M}$ range with a correlation coefficient $\left(\mathrm{R}^{2}\right)$ of 0.995 and a detection limit of $0.5 \mu \mathrm{M}$. We note that the phosphate in the fertilizer was directly measured in the complex matrix without separation.

\section{[Figure 6]}

\section{Conclusions}

In summary, we report a sensitive and specific sensing method to detect phosphate ions in aqueous media using the $\mathrm{SiO}_{2} @ \mathrm{TMS}-\mathrm{EDTA} @ \mathrm{Gd}^{3+}$ nanoparticles. The $\mathrm{SiO}_{2} @ \mathrm{TMS}-\mathrm{EDTA} @ \mathrm{Gd}^{3+}$ nanoparticles have excellent water dispersibility and colloidal stability at physiological $\mathrm{pH}$, which

allows their use in biological systems. The $\mathrm{Gd}^{3+}$ ions in the $\mathrm{SiO}_{2} @ \mathrm{TMS}-\mathrm{EDTA} @ \mathrm{Gd}^{3+}$ nanoparticles serve as both the contrast agent for nuclear magnetic relaxation and the phosphate recognition element. 
The method has high selectivity towards phosphate ions over many other common anions. We also demonstrate that it can detect phosphate in fertilizer quantitatively with a detection limit of $0.5 \mu \mathrm{M}$ without separation. The results pave way for further development and usage of similar types of paramagnetic nanoparticles for nuclear magnetic relaxation based sensing.

\section{Acknowledgement}

This work is partially supported by the US National Science Foundation (CBET-1065633). We thank Erika Reith and Dr. Necati Kaval for helpful discussions.

\section{References}

1. Hargrove, A.E; Nieto, S.; Zhang, T.; Sessler, J.L.; Anslyn, E.V. Artificial receptors for the recognition of phosphorylated molecules. Chem. Rev., 2011, 111, 6603-6782.

2. Beer, P.D.; Hayes, E.J. Transition metal and organometallic anion complexation agents Coord. Chem. Rev., 2003, 240, 167-189.

3. Sharpley, A.N.; Daniel, T.C.; Sims, J.T.; Pote, D.H. Determining environmentally sound soil phosphorus levels. J. Soil \& Water Conservation, 1996, 51, 160-166.

4. Schindler, D.; Vallentyne, J.R. Over fertilization of the World's freshwaters and estuaries, University of Alberta Press, 2008.

5. Chislock, M.F.; Doster, E.; Zitomer, R.A.; Wilson, A.E. Nature Education Knowledge, 2013, $4(4), 10$. 
6. Carpenter, S.R.; Caraco, N.F.; Smith, V.H. Nonpoint pollution of surface waters with phosphorus and nitrogen. Ecological Applications, 1998, 8, 559-568.

7. Tiessen, H. The Ecophysiology of Plant-Phosphorus Interactions, Wiley: New York, 1995, 7, 17.

8. http://pubs.usgs.gov/circ/circ1136/circ1136.html

9. Dodds, W. K.; Bouska, W.W.; Eitzmann, J.L.; Pilger, T.J.; Pitts, K.L.; Riley, A.J.; Schloesser, J.T.; Thornbrugh, D.J. Eutrophication of U.S. Freshwaters: Analysis of potential economic damages. Environ. Sci. Technol. 2009, 43, 12-19.

10. Shumway, S. E. A review of the effects of algal blooms on shellfish and aquaculture. J. World Aquaculture Society, 1990, 21, 65-104.

11. Bartram, J.; Carmichael, W.W.; Chorus; I.; Jones, G.; Skulberg, O.M. Toxic Cyanobacteria in Water: A guide to their public health consequences, monitoring and management. World Health Organization, 1999.

12. Warwick, C.; Guerreiro, A.; Soares, A. Sensing and analysis of soluble phosphates in environmental samples: A review. Biosens. Bioelectron., 2013, 41, 1-11.

13. Udnan, Y.; McKelvie, I.D.; Grace, M.R.; Jakmunee, J.; Grudpan, K. Evaluation of on-line preconcentration and flow-injection amperometry for phosphate determination in fresh and marine waters. Talanta, 2005, 66, 461-466.

14. Rahman, M.A.; Park, D.S.; Chang, S.C.; McNeil, C.J.; Shim, Y.B. The biosensor based on the pyruvate oxidase modified conducting polymer for phosphate ions determinations. Biosens. Bioelectron., 2006, 21, 1116-1124. 
15. Lee, H.N.; Xu, Z.; Kim, S.K.; Swamy, K.M.K.; Kim, Y.; Kim, S.J.; Yoon, J. Pyrophosphateselective fluorescent chemosensor at physiological pH: Formation of a unique excimer upon addition of pyrophosphate. J. Am. Chem. Soc., 2007, 129, 3828-3829.

16. Ikebukuro, K.; Nishida, R.; Yamamoto, H.; Arikawa, Y.; Nakamura, H.; Suzuki, M.; Kubo, I.; Takeuchi, T.; Karube, I. A novel biosensor system for the determination of phosphate. $J$. Biotechnology, 1996, 48, 67-72.

17. Han, M.S.; Kim, D.H. Naked-Eye Detection of Phosphate Ions in Water at Physiological pH: A Remarkably Selective and Easy-To-Assemble Colorimetric Phosphate-Sensing Probe. Angew. Chem. Int. Ed., 2002, 41, 3809-3811.

18. Masson, P.; Morel, C.; Martin, E.; Oberson, A.; Friesen, D. Comparison of soluble P in soil water extracts determined by ion chromatography, colorimetric, and inductively coupled plasma techniques in PPB range. Commun. Soil Sci. Plant Anal. 2001, 32, 2241-2253.

19. Zhao, H.X.; Li Qin Liu, L.Q.; Liu, Z.D.; Wang, Y.; Zhao' X.J.; Huang, C.Z. Highly selective detection of phosphate in very complicated matrixes with an off-on fluorescent probe of europium-adjusted carbon dots. Chem. Commun., 2011, 47, 2604-2606.

20. Kwan, R.C.H ; Leung, H.F ; Hon, P.Y.T. ; Barford, J.P.; Renneberg, R. A screen-printed biosensor using pyruvate oxidase for rapid determination of phosphate in synthetic wastewater. Appl. Microbiology\& Biotechnology, 2005, 66, 377-383.

21. Bianchi, A.; Bowman-James, K.; Garcia-Espana, E. Supramolecular Chemistry, Wiley-VCH, New York, 1997.

22. Lee, H.; Sun, E.; Ham, D.; Weissleder, R. Chip-NMR biosensor for detection and molecular analysis of cells. Nat Med., 2008, 14, 869-874. 
23. Ling, Y.; Vassiliou, C.C.; Cima, M.J. Magnetic relaxation-based platform for multiplexed assays. Analyst, 2010, 135, 2360-2364.

24. Hogemann, D.; Ntziachristos, V.; Josephson, L.; Weissleder, R. High throughput magnetic resonance imaging for evaluating targeted nanoparticle probes. Bioconjug. Chem., 2002, 13, 116-121.

25. Taktak, S.; Sosnovik, D.; Cima, M.J.; Weissleder, R.; Josephson, L. Multiparameter magnetic relaxation switch assays. Anal. Chem., 2007, 79, 8863-8869.

26. Perez, J.M.; Simeone, F.J.; Saeki, Y.; Josephson, L., Weissleder, R. Viral-induced self-assembly of magnetic nanoparticles allows the detection of viral particles in biological media. J. Am. Chem. Soc., 2003, 125, 10192-10193.

27. Perez, J.M.; Josephson, L.; O’Loughlin, T.; Hogemann, D.; Weissleder, R. Magnetic relaxation switches capable of sensing molecular interactions. Nat. Biotechnol., 2002, 20, 816-820.

28. Kaittanis, C.; Santra, S.; Santiesteban, O.J.; Henderson, T.J.; Perez, J.M. The assembly state between magnetic nanosensors and their targets orchestrates their magnetic relaxation response. J. Am. Chem. Soc., 2011, 133, 3668-3676.

29. Tsourkas, A.; Hofstetter, O.; Hofstetter, H.; Weissleder, R.; Josephson, L. Magnetic relaxation switch immunosensors detect enantiomeric impurities. Angew. Chem. Int. Ed. , 2004, 43, 2395 2399.

30. Sun, E.Y.; Weissleder, R.; Josephson, L. Continuous analyte sensing with magnetic nanoswitches. Small, 2006, 2, 1144-1147.

31. Haun, J.B.; Yoon, T.J.; Lee, H.; Weissleder, R. Magnetic nanoparticle biosensors. Wiley Interdiscip Rev Nanomed Nanobiotechnol., 2010, 2, 291-304. 
32. Werner, E.J.; Datta A.; Jocher, C.J.; Raymond, K.N. High-relaxivity MRI contrast agents: where coordination chemistry meets medical imaging. Angew. Chem. Int. Ed., 2008, 47, 8568-8580.

33. Xue, S.; Qiao, J.; Pu, F.; Cameron, M.; Yang, J.J. Design of a novel class of protein-based magnetic resonance imaging contrast agents for the molecular imaging of cancer biomarkers. Wiley Interdiscip. Rev Nanomed. Nanobiotechnol., 2013, 163-179.

34. Ozkaya-Ahmadov, T.; Joshi, P.; Zhang, J.; Nahan, K.; Caruso, J.A.; Zhang, P. Paramagnetic relaxation based biosensor for selective dopamine detection. Chem. Commun., 2015, 51, 11425 11428.

35. Bonnet, C.S.; Toth, E. The chemistry of contrast agents in medical magnetic resonance Imaging, 2014.

36. Franz, K.J.; Wang, Q. Inorganic Chemical Biology: Principles, Techniques and Applications, 2014.

37. Aime, S.; Caravan, P. Biodistribution of gadolinium-based contrast agents, including gadolinium deposition. J. Magn. Reson. Imaging. 2009, 30, 1259-1267.

38. Burai, L.; Hietapelto, V.; Király, R.; Tóth, E.; Brücher, E. Stability constants and 1H relaxation effects of ternary complexes formed between Gd-DTPA, Gd-DTPA-BMA, Gd-DOTA, and GdEDTA and citrate, phosphate, and carbonate ions. Magn. Reson. Med., 1997, 38, 146-150.

39. Sherry A.D.; Caravan, P.; Lenkinski, R.E. Primer on Gadolinium chemistry. J Magn. Reson. Imaging, 2009, 30, 1240-1248.

40. Rohrer, M.; Bauer, H.; Mintorovitch, J.; Requardt, M.; Weinmann, H.J. Comparison of magnetic properties of MRI contrast media solutions at different magnetic field strengths. Investigative Radiology, 2005, 40, 715-724. 
41. Hermanson, G.T. Bioconjugate Techniques, 2nd Edition, Academic Press, 2008, 1202.

42. Kulkarni, A.A.; Weiss, A.A.; Iyer, S.S. Detection of carbohydrate binding proteins using magnetic relaxation switches. Anal. Chem. 2010, 82, 7430-7435.

43. Pierre, V.C.; Melchior, M.; Doble, D.M.; Raymond, K.N. Toward optimized high-relaxivity MRI agents: thermodynamic selectivity of hydroxypyridonate/catecholate ligands. Inorg Chem., 2004, 43, 8520-8525.

44. Bamrungsap, S.; Chen, T.; Shukoor, M.I.; Chen, Z.; Sefah, K.; Chen, Y.; Tan, W. Pattern recognition of cancer cells using aptamer-conjugated magnetic nanoparticles. ACS Nano, 2012, 6, 3974-3981.

\section{Figure caption}

Figure 1. Schematic representation of the detection mechanism. Phosphate binding to $\mathrm{SiO}_{2} @ \mathrm{TMS}$ EDTA@ $\mathrm{Gd}^{3+}$ nanoparticles leads to the increase of $\mathrm{T}_{2}$ relaxation time of water protons.

Figure 2. TEM images of the $\mathrm{SiO}_{2} @ \mathrm{TMS}-\mathrm{EDTA} @ \mathrm{Gd}^{3+}$ nanoparticles. Scale bar is $100 \mathrm{~nm}$.

Figure 3. $\mathrm{R}_{2}$ relaxivity measurement of $\mathrm{SiO}_{2} @ \mathrm{TMS}-\mathrm{EDTA} @ \mathrm{Gd}^{3+}$ nanoparticles.

Figure $4 . \Delta \mathrm{T}_{2} \%$ as a function of phosphate concentration in tris buffer.

Figure 5. Specificity test of the phosphate sensing. $\Delta \mathrm{T}_{2} \%$ after adding various anions to the $\mathrm{SiO}_{2} @ \mathrm{TMS}-\mathrm{EDTA} @ \mathrm{Gd}^{3+}$ nanoparticle solution at pH 7.5.

Figure $6 . \Delta \mathrm{T}_{2} \%$ as a function phosphate concentration of fertilizer in tris buffer. 
Novelty statement:

We report a novel nuclear magnetic relaxation-based sensing method for sensitive and selective detection of phosphate ions in aqueous media, which can quickly detect phosphate ions at physiological $\mathrm{pH}$ quantitatively, even in a commercial fertilizer without separation. 


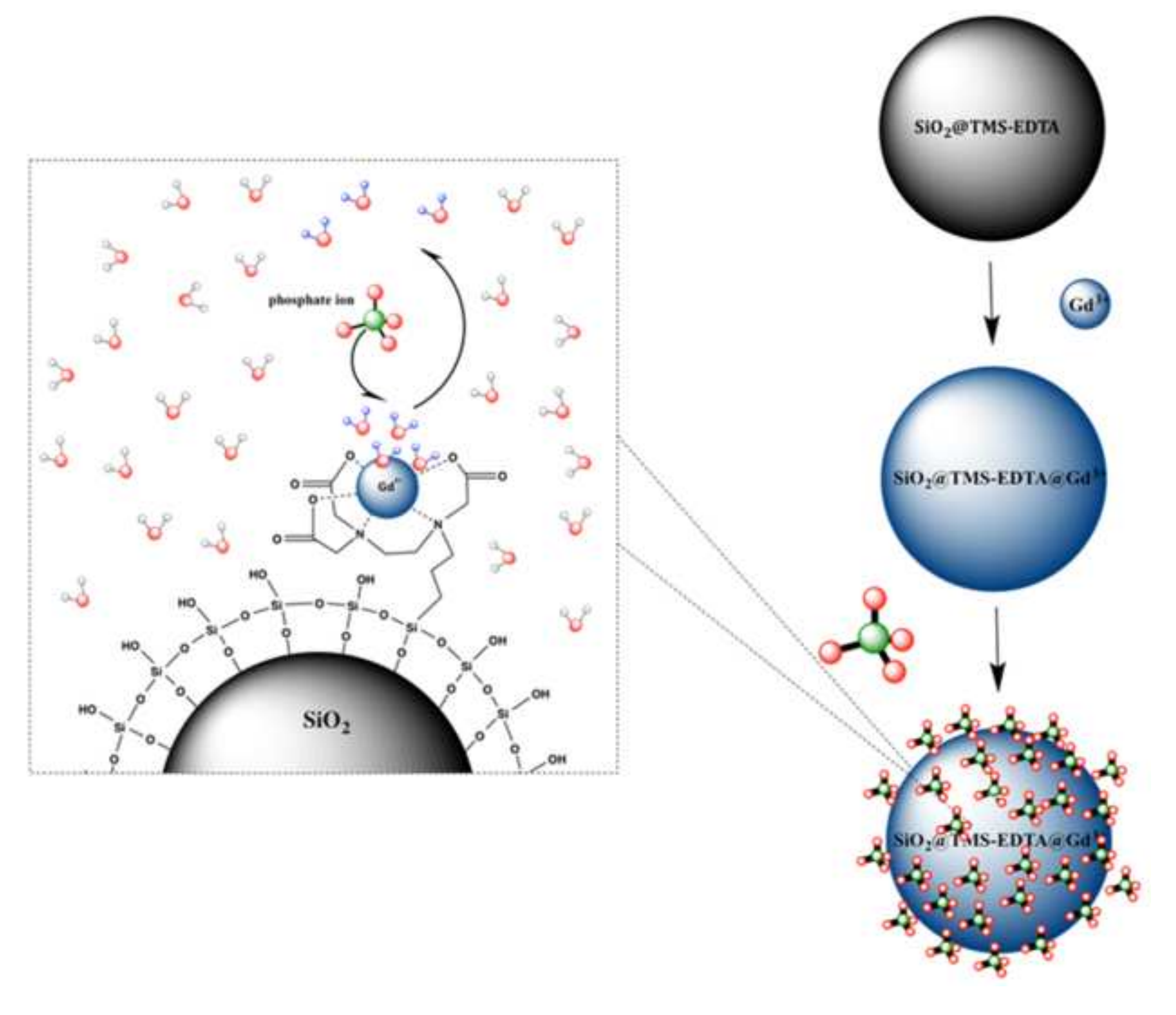

$\mathrm{SiO}_{2}$ @TMS-EDTA

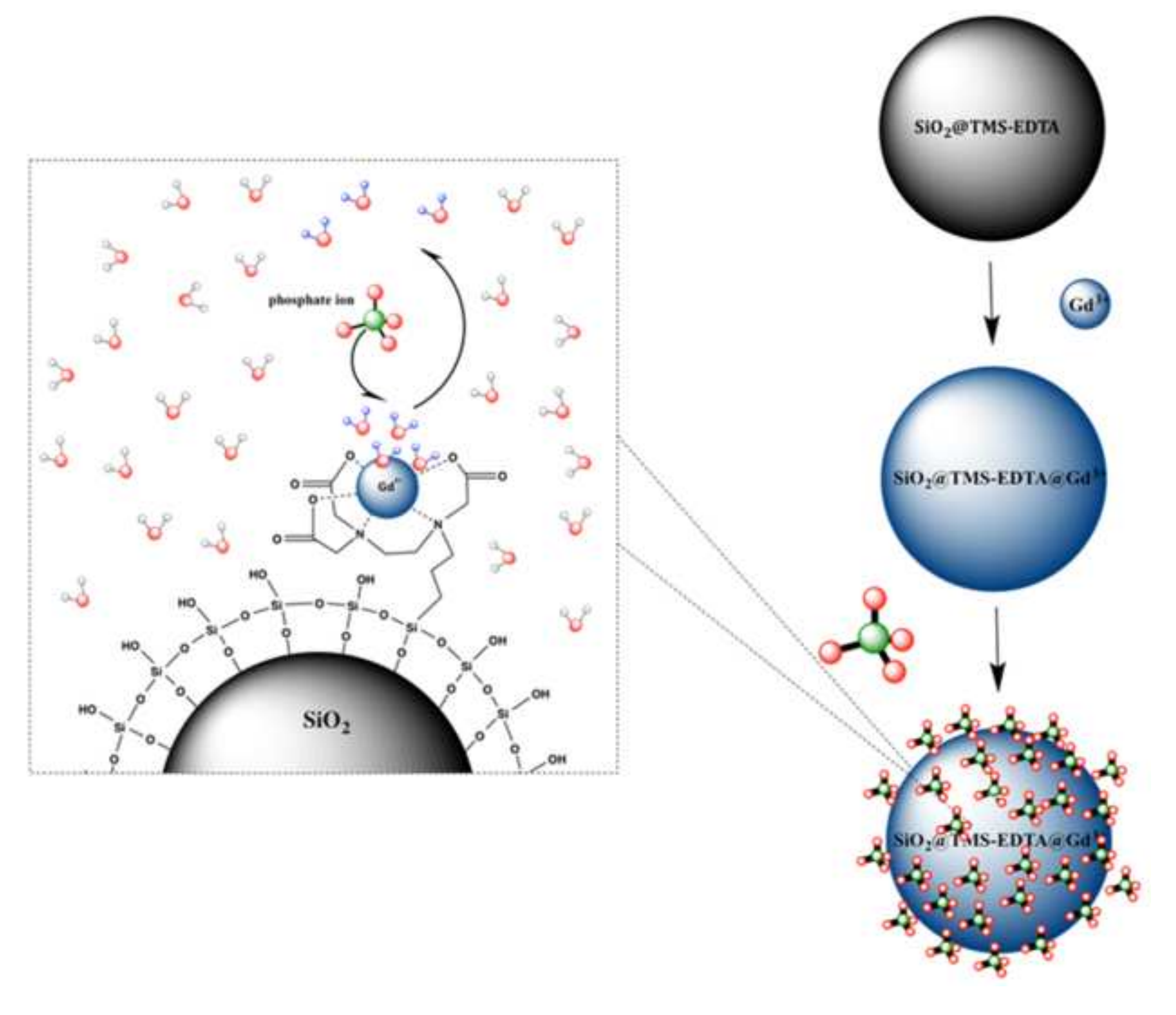

$\mathrm{SiO}_{2} \propto$ TMS-EDTA $\odot \mathrm{Gd}$
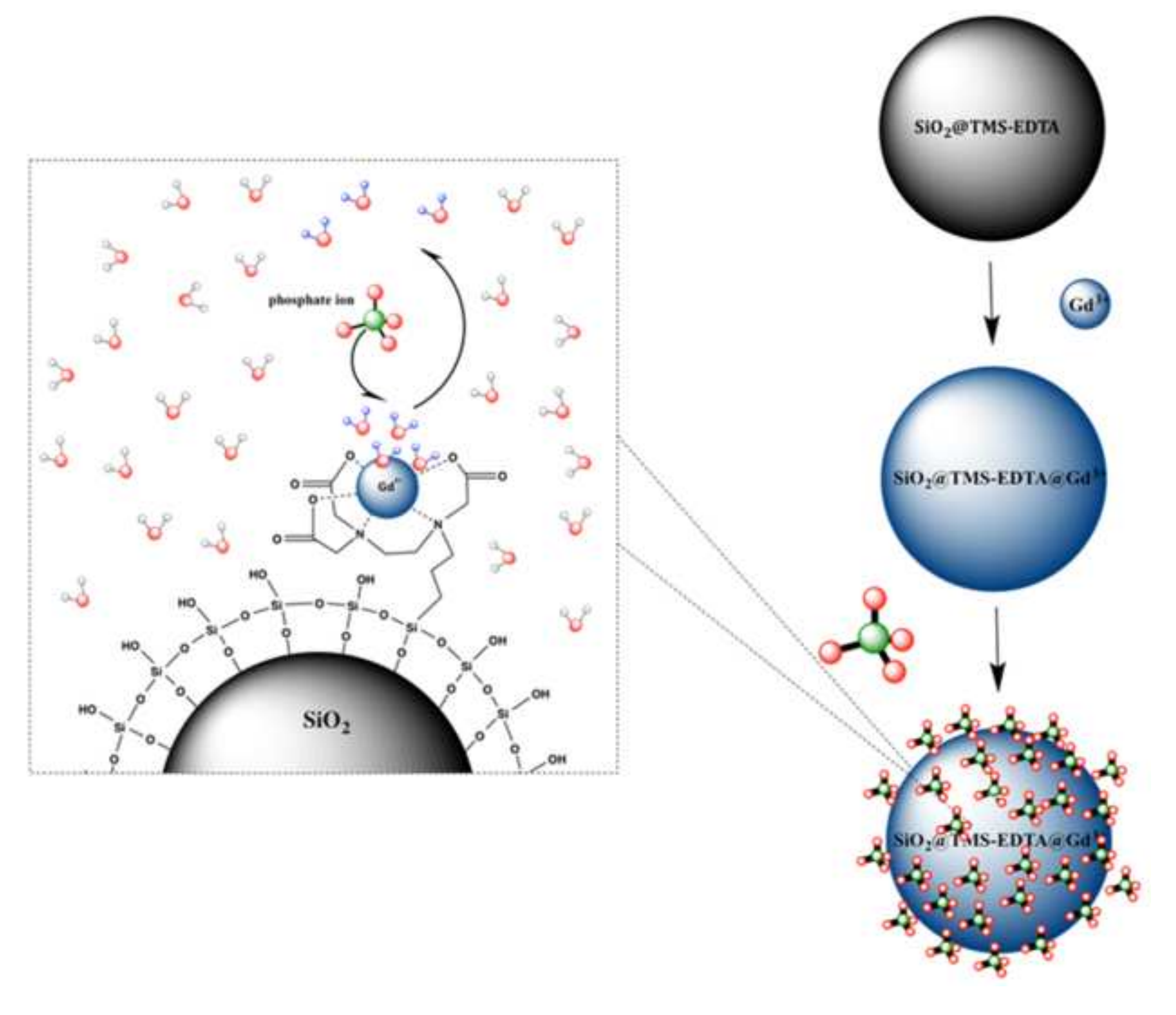


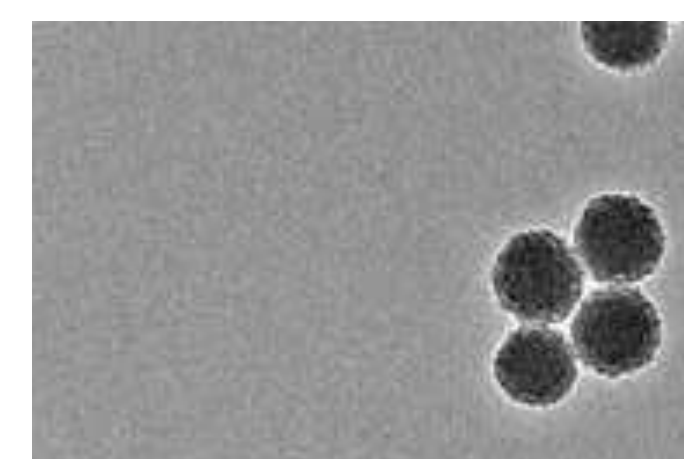

88
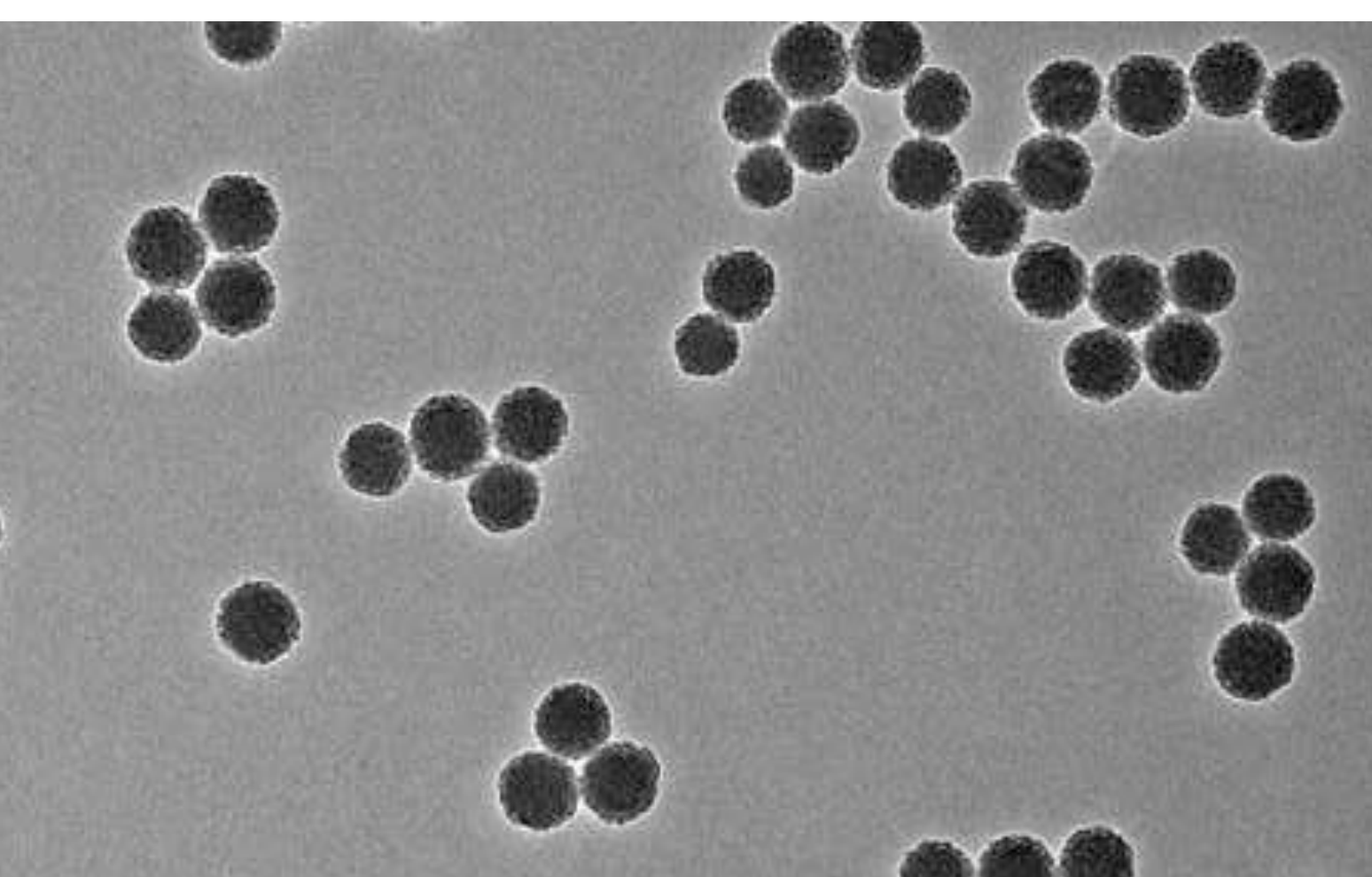

-
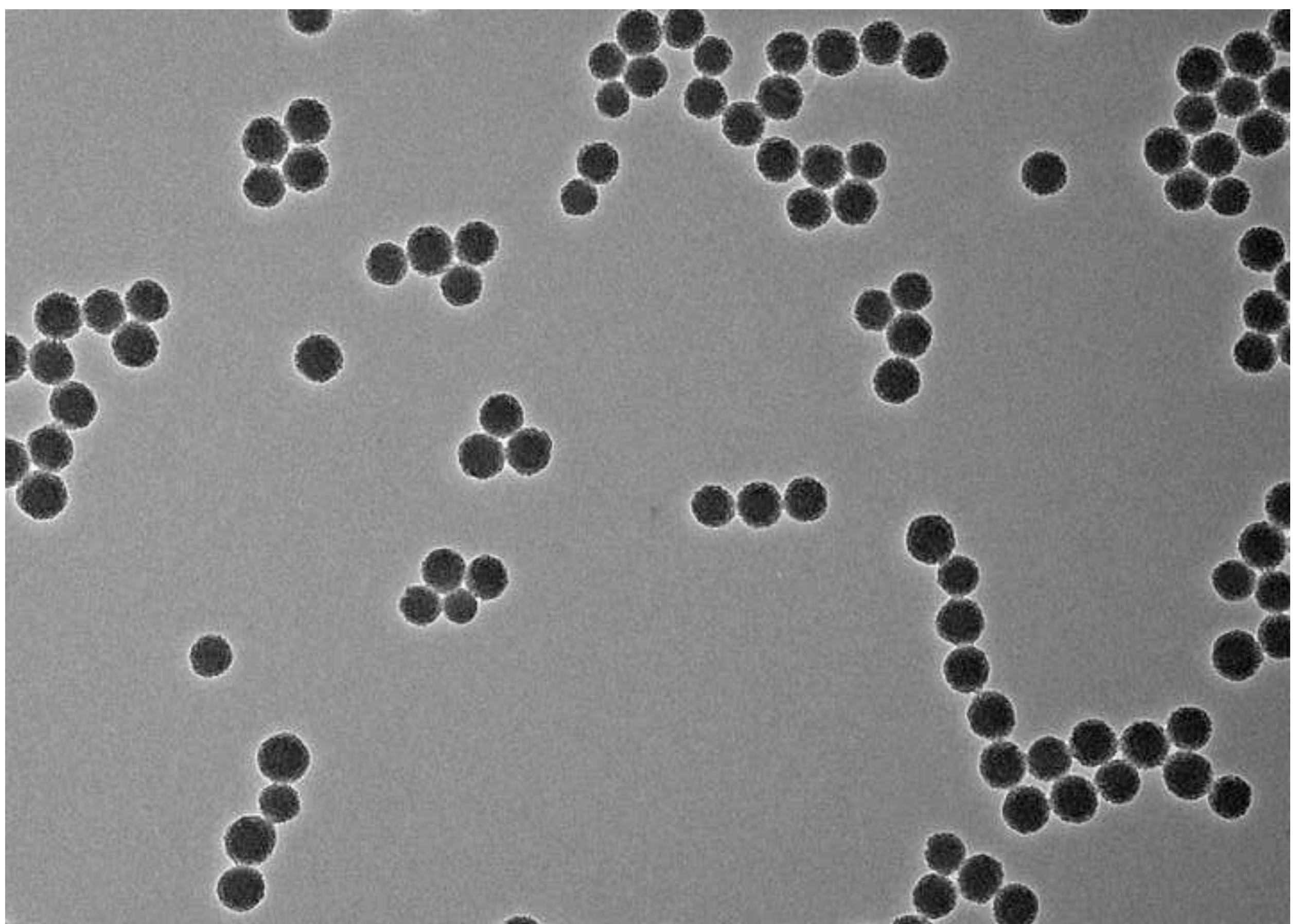

$100 \mathrm{~mm}$

\section{$\infty$}
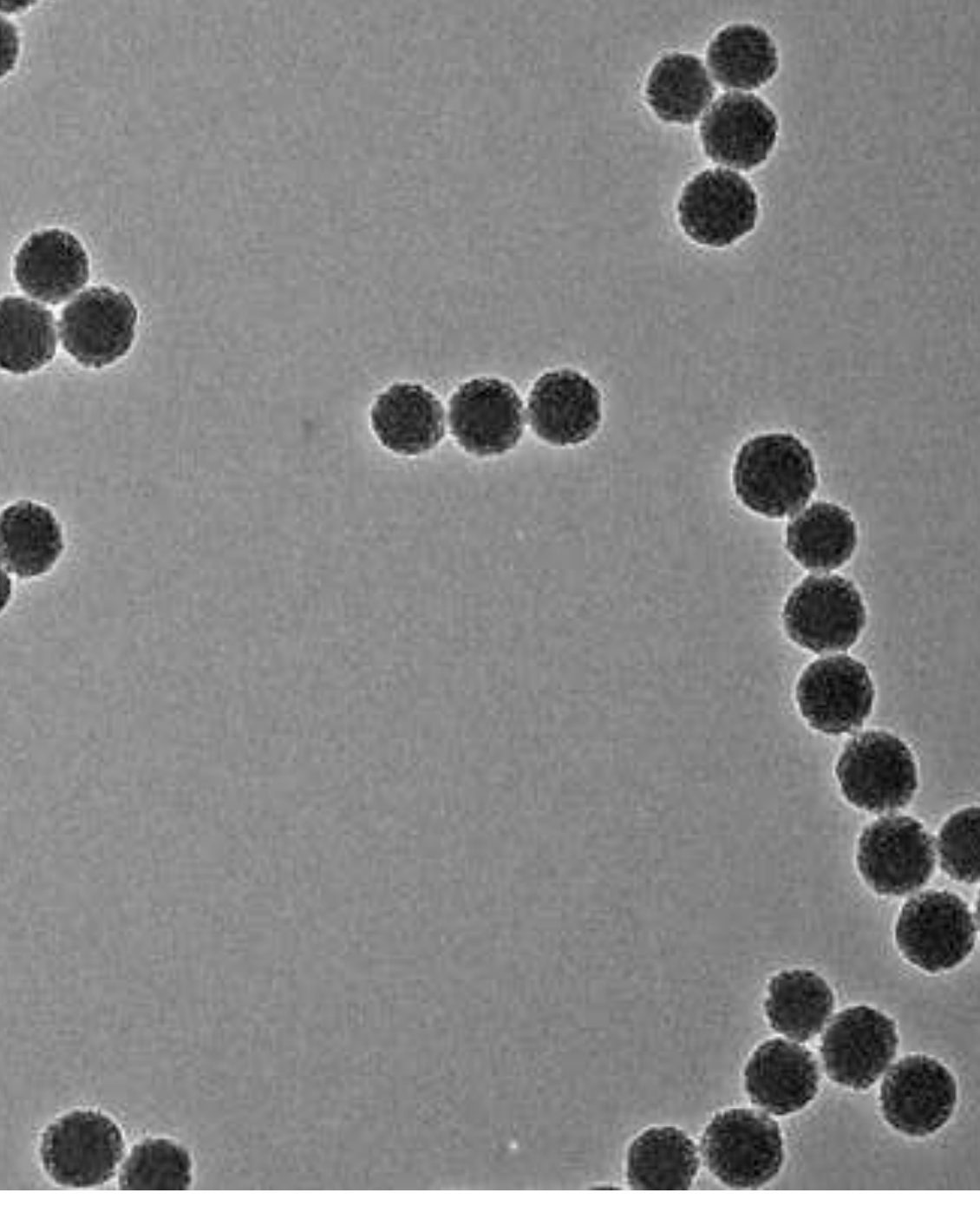


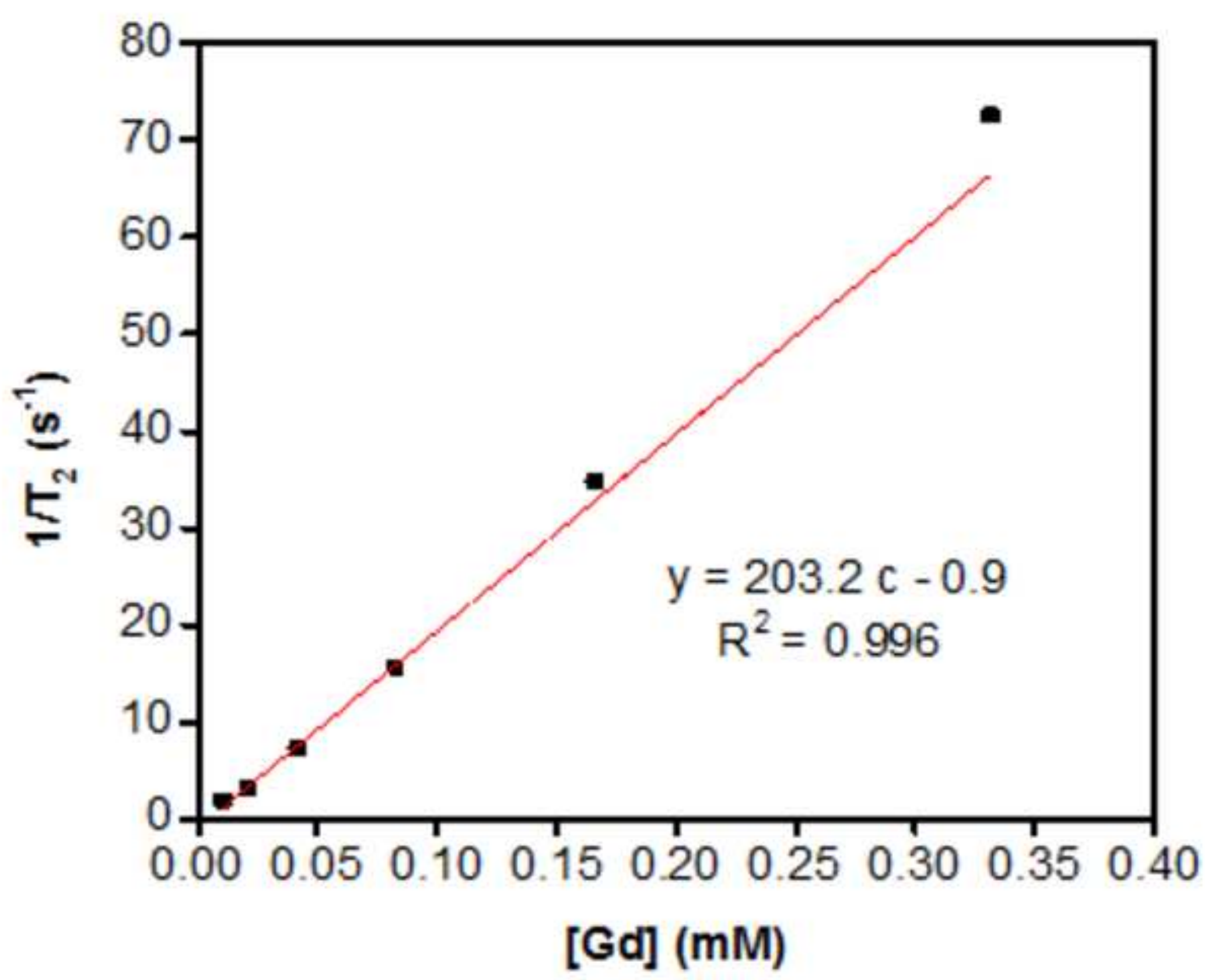




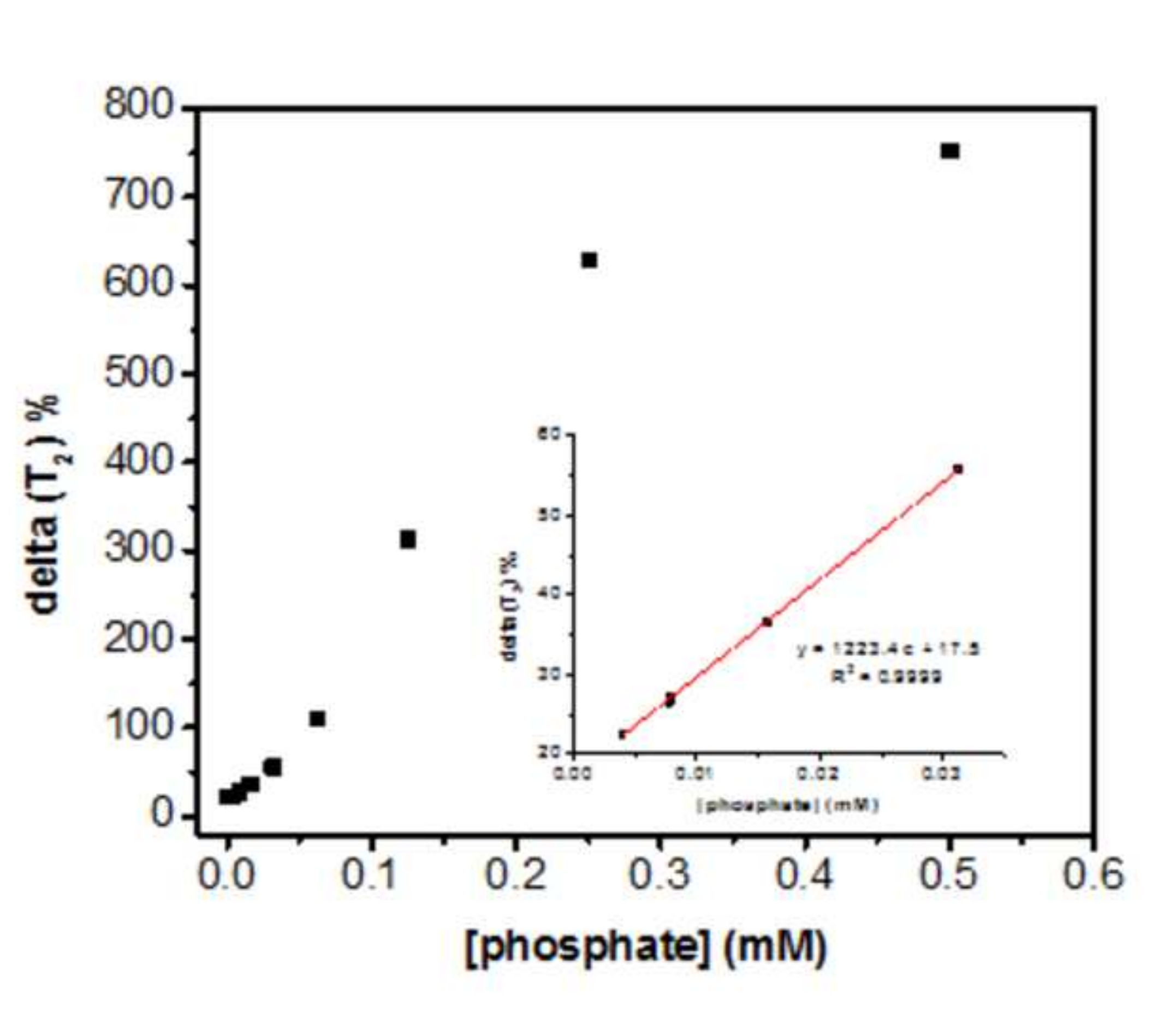

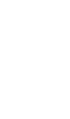

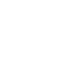

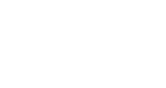

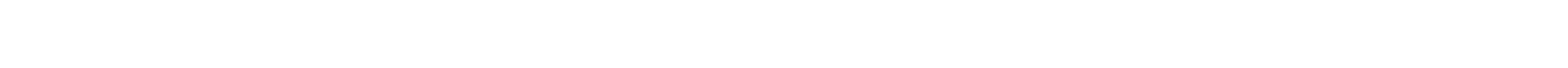
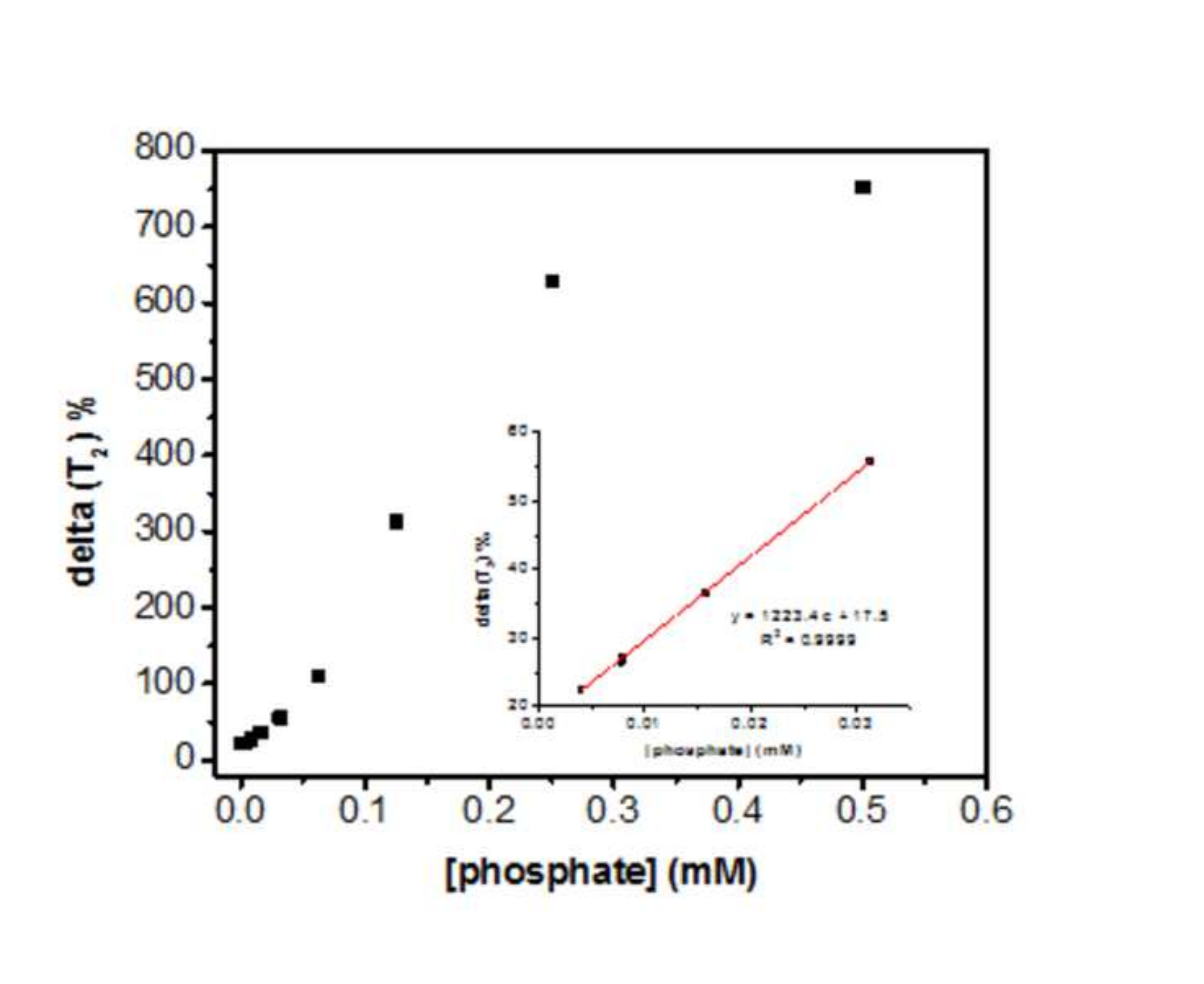

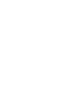
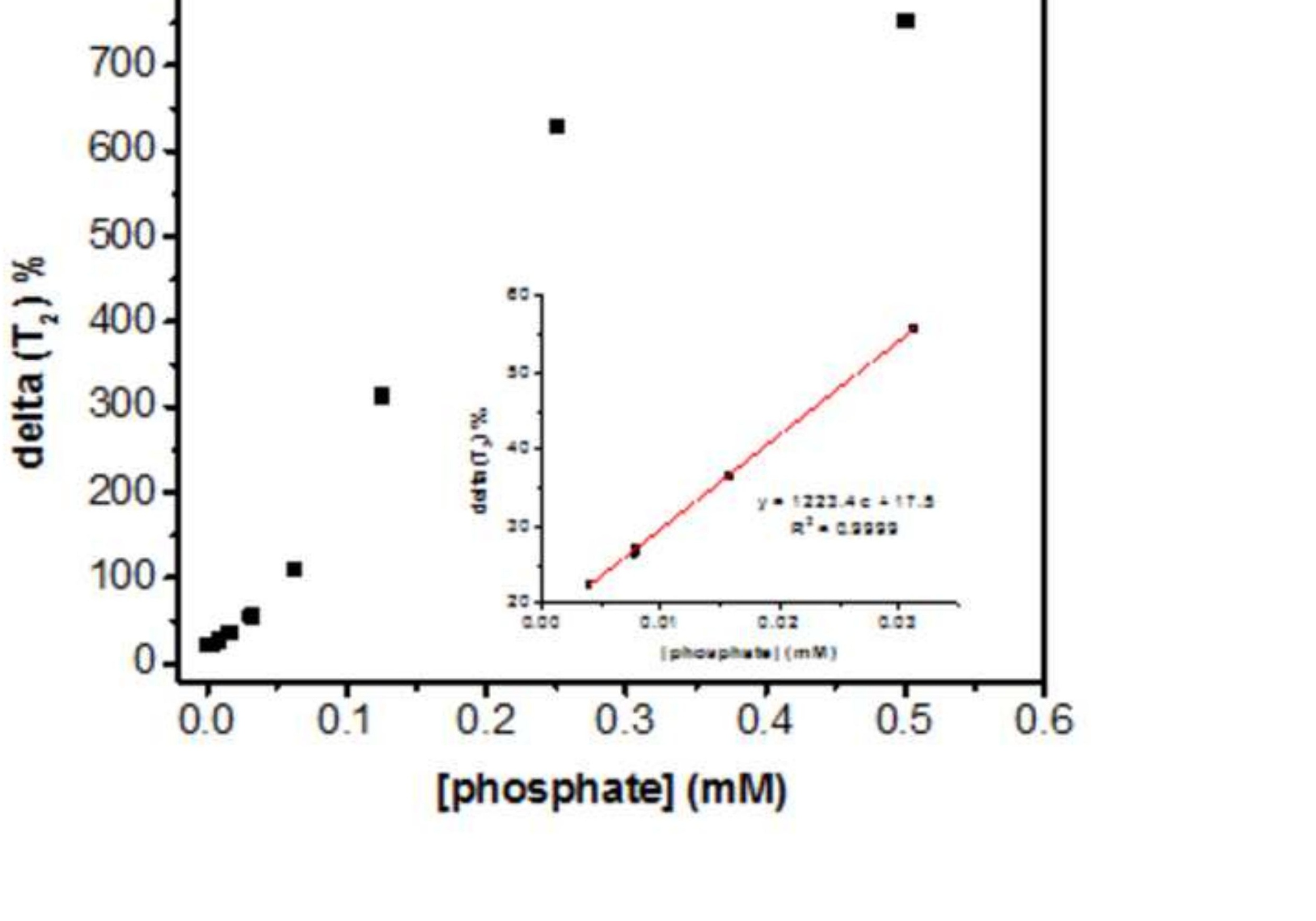

e 


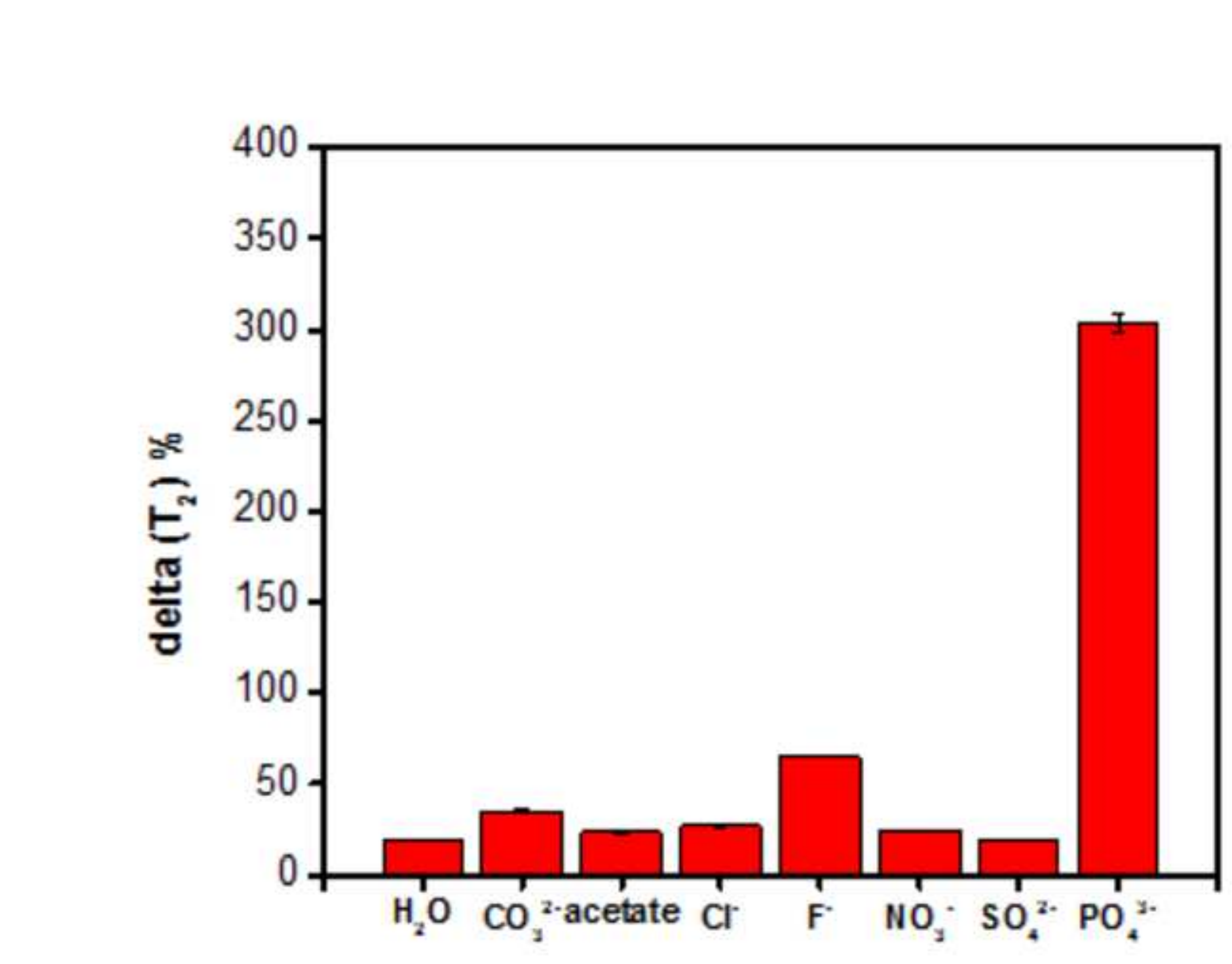

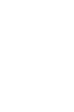

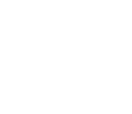




\section{Magnetic Relaxation-Based Sensing of Phosphate Ion}

Tevhide Ozkaya Ahmadov, Peng Wang, Haohan Zhao, Peng Zhang

Department of Chemistry, University of Cincinnati, Cincinnati, OH 45221

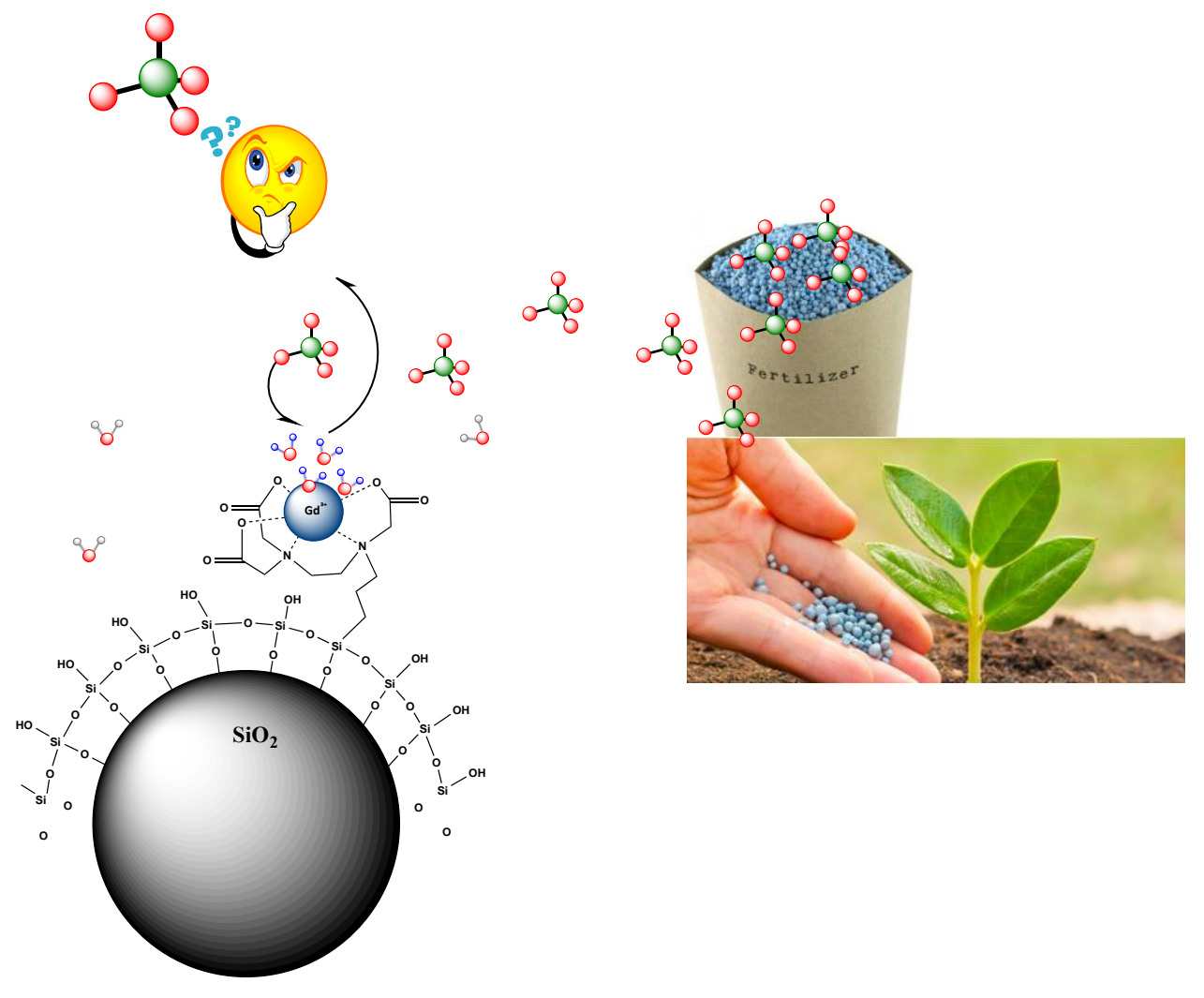

